\title{
Effect of a Strategically Positioned Methoxy Substituent on the Photochemistry of 3-Aryl-3H-1-Oxacyclopenta[l]Phenanthren-2-Ones
}

\author{
Roshini K. Thumpakara, ${ }^{1}$ Binoy Jose, ${ }^{1}$ Perupparampil A. Unnikrishnan, ${ }^{1}$ \\ Sreedharan Prathapan, ${ }^{1}$ and Nigam P. Rath ${ }^{2}$ \\ ${ }^{1}$ Department of Applied Chemistry, Cochin University of Science and Technology, Kochi 682022, India \\ ${ }^{2}$ Department of Chemistry and Biochemistry, University of Missouri-St. Louis, St. Louis, MO 63121, USA \\ Correspondence should be addressed to Roshini K. Thumpakara, roshinikt@gmail.com
}

Received 29 September 2010; Accepted 24 November 2010

Academic Editor: Dipakranjan Mal

Copyright (C 2010 Roshini K. Thumpakara et al. This is an open access article distributed under the Creative Commons Attribution License, which permits unrestricted use, distribution, and reproduction in any medium, provided the original work is properly cited.

Irradiation of 3-methoxy-3-aryl-3H-1-oxacyclopenta[l]phenanthren-2-one derivatives 5a-d resulted in singlet-mediated decarbonylation reaction leading to the formation of phenanthrene derivatives $9 \mathbf{a}-\mathbf{d}$. The structure of the photoproduct was unequivocally established on the basis of X-ray crystallographic analysis.

\section{Introduction}

The photochemistry of unsaturated $\gamma$-lactones such as $2(3 \mathrm{H})$ - and $2(5 \mathrm{H})$-furanones (see Scheme 1 ) is well established [1-8]. Depending on structural features and irradiation conditions, such lactones undergo several phototransformations including decarbonylation [1], decarboxylation [9], solvent addition to the double bond [10], migration of aryl substituents [11], and dimerisation [12]. It has been established that decarbonylation is a singlet-mediated reaction, while aryl group migration, dimerisation, and solvent addition reactions are triplet mediated [13, 14]. Chapman and McIntosh have noted that a critical requirement for clean photochemical cleavage of the acyl-oxygen bond is the presence of a double bond adjacent to the ether oxygen [6]. Stabilization of the incipient oxy radical was considered to be a determining factor in the photocleavage of the bond. While $2(3 \mathrm{H})$-furanones possessing this structural requirement undergo facile decarbonylation reaction, $2(5 \mathrm{H})$-furanones are reluctant to undergo decarbonylation. In principle, it should be possible to further enhance the propensity of $2(3 \mathrm{H})$-furanones to undergo decarbonylation by introducing radical-stabilizing groups at appropriate position on the furanone ring. In this paper, we describe a successful validation of this hypothesis.

Though 3,3,5-triarylfuranones 1 undergo phototransformations characteristic of $2(3 \mathrm{H})$-furanones, related phenanthrofuranones such as 2 are reluctant to undergo further phototransformations and hence are occasionally isolated as photostable end products in certain photochemical transformations [3-5]. We reasoned that introduction of a radical-stabilizing methoxy group at the 3-position of phenanthrofuranones as in $\mathbf{3}$ should enhance their propensity to undergo decarbonylation by stabilization of the putative radical center at the 3-position. This hypothesis has literature precedence. In the case of carbonyl compounds, Wagner has established that $\gamma$-alkoxy substituents enhance the rate of $\gamma$-hydrogen abstraction (leading to Norrish Type II cleavage) and appropriately positioned alkoxy substituents facilitate rare- $\delta$-hydrogen abstraction reactions $[15,16]$. In the present study, we have examined the photochemistry of a few phenanthro-2 $(3 \mathrm{H})$-furanones having a methoxy substituent at the 3-position to assess the role of the methoxy substituents in facilitating light-induced acyl-oxygen bond cleavage in phenanthro- $2(3 \mathrm{H})$-furanones. Required phenanthro-2(3H)-furanone derivatives 3 were 
<smiles>O=C1CC=CO1</smiles>

2(3H)-furanone

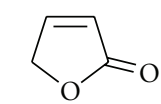

2(5H)-furanone
Scheme 1

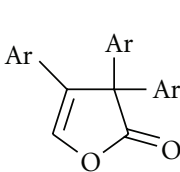

1

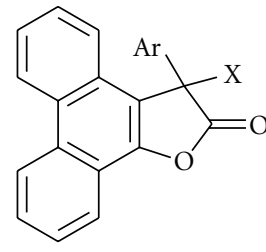

$2 \mathrm{X}=\mathrm{H}$

$3 \mathrm{X}=\mathrm{OCH}_{3}$

Scheme 2

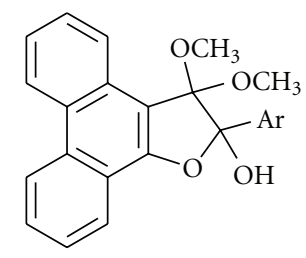

4 synthesized by the neat thermolysis of the corresponding phenanthro-2,3-dihydro-2-furanol derivatives 4 , which in turn were generated by the condensation of phenanthrenequinone with acetophenones (see Scheme 2) [17].

The photolysis $(\lambda=300 \mathrm{~nm})$ of $2(3 \mathrm{H})$-furanones $5 \mathbf{a}-$ d in benzene gave 10-hydroxy-phenanthren-9-yl methanone derivatives $\mathbf{9 a -} \mathbf{d}$ as yellow crystalline compounds in moderate yields (64\%-68\%) (Scheme 3). Structures of 9a-d were arrived at on the basis of spectral and analytical data. IR spectrum of $\mathbf{9 a}-\mathbf{d}$ showed the presence of hydroxyl and carbonyl group in the molecule. ${ }^{13} \mathrm{C}$ NMR spectrum also showed a peak at $\delta 199$ confirming the presence of a carbonyl carbon. The structure of these compounds was unequivocally determined by single crystal X-ray diffraction analysis of a representative example such as $\mathbf{9 b}$ (see Figure 1). The unusually low carbonyl stretching frequency observed $\left(1620 \mathrm{~cm}^{-1}\right)$ is attributable to strong intramolecular hydrogen bonding interaction between hydroxyl and carbonyl groups present in the molecule. This was further corroborated by the $\mathrm{D}-\mathrm{H} \cdots \mathrm{A}$ distances and angle around $\mathrm{H}$ atoms $\left(\mathrm{O} 1-\mathrm{H} 1 \cdots \mathrm{O} 2=1.731 \AA\right.$, 145.9; $\mathrm{O} 1{ }^{\prime \prime}-$ $\left.\mathrm{H} 1{ }^{\prime} \cdots \mathrm{O} 2{ }^{\prime}=1.745 \AA, 148.9\right)$ as determined from the Xray structure. The standard deviation of $\mathrm{H}$-bond donoracceptor distance was calculated, and it was found to be 0.007 . The compound crystallizes in monoclinic space group $\mathrm{P} 2{ }_{1}$ with two unique molecules in the asymmetric unit. As $Z^{\prime}>1$, molecular overlay was used to look for differences in the two unique molecules. The overlay (OFIT, Shelxtl) shows that the phenanthrene rings match very well (weighted RMS deviation $=0.0174)$. The molecules start to diverge after the carbonyl group $\left(\mathrm{C} 16-\mathrm{C} 16^{\prime}=0.143 \AA\right.$, C19-C19' $=0.415 \AA$ ). The two unique molecules in the asymmetric unit use the methoxy oxygen and an $\mathrm{H}$ atom of the phenanthrene ring to form 1-D chain mediated through $\mathrm{C}-\mathrm{H} \cdots \mathrm{O}$ contacts. These chains are interconnected to form square-like network (see Figure 2). Each square is formed by two different symmetry-independent molecules, and hence the square is not symmetrical $\left(\mathrm{O}^{\prime} /--\mathrm{H} 11^{\prime}(x\right.$, $y-1, z)=2.465, \mathrm{O} 3--\mathrm{H} 12(x, y-1, z)=2.688, \mathrm{O} 2{ }^{\prime}-$ $-\mathrm{H} 22 \mathrm{~b}(x, y+1, z)=2.595, \mathrm{O} 2-\mathrm{H} 22 \mathrm{~d}(x, y-1, z)$ $=2.694 \AA$, standard deviation of H-bond donor-acceptor distance 0.093).

The formation of photoproducts $\mathbf{9 a}-\mathbf{d}$ on irradiation in benzene or acetone can be understood in terms of the pathways shown $[6,13]$ (see Scheme 3 ). The initial excitation of the $2(3 \mathrm{H})$-furanones to the corresponding singlet-excited state resulted in decarbonylation to the diradical intermediate 7 which undergoes bond reorganization to give the quinonemethide intermediate 8 . It appears that the methoxy group has a major role to play on the facile decarbonylation of furanones vis-à-vis other phenanthrofuranones such as 2. Hydrolytic elimination of methanol followed by tautomerization will eventually lead to $\mathbf{9}$. The phototransformation of $\mathbf{5 a}$ to $\mathbf{9 a}$ is not quenched by ferrocene $\left(E_{T} \approx 40 \mathrm{Kcal} \mathrm{mol}^{-1}\right)$ indicating a singletmediated pathway for the observed transformation. Since the phenanthrenefuranones $\mathbf{5 a - d}$ absorbed strongly in the 220-400 nm range, it was not feasible to carry out sensitized irradiation of these compounds using common sensitizers.

In order to generate further support for the involvement of intermediates such as $\mathbf{7}$ and $\mathbf{8}$, we attempted to trap them. Our attempts to trap the quinonemethide intermediate 8 by a $4+2$ cycloaddition reaction with DMAD, however, were not successful. We conclude that the hydrolysis of the vinyl ether component in $\mathbf{8}$ is much faster than the cycloaddition reaction under the reaction conditions applied by us. A good hydrogen atom donor such as 2-propanol was used to trap radical intermediate 7 by $H$-transfer. However, trapping experiment using 2-propanol was unsuccessful indicating the reactive nature of 7 . Though the proposed intermediates could not be intercepted, the photochemical transformation of $\mathbf{5 a - d}$ involving acyl-oxygen bond cleavage appears to be analogous to that of other $2(3 \mathrm{H})$-furanones $[6,7,9,10]$.

In conclusion, we have synthesized several phenanthro$2(3 \mathrm{H})$-furanone derivatives and examined their photochemistry. We have demonstrated that the methoxy group in the lactone ring has a profound effect on the acyl-oxygen bond cleavage leading to decarbonylation reaction. Our attempts to trap the proposed intermediates by using DMAD and 2propanol were unsuccessful presumably due to their reactive nature.

\section{Experimental}

All melting points are uncorrected and were determined on a Neolab melting point apparatus. All reactions and chromatographic separations were monitored by thin layer chromatography (TLC). Glass plates coated with dried and activated silica gel or aluminium sheets coated with silica gel (Merck) were used for thin layer chromatography. Visualization was achieved by exposure to iodine vapours or UV radiation. Column chromatography was carried out with slurry-packed silica gel (Qualigens, 60-120 mesh). Absorption spectra were recorded using Shimadzu 160A spectrometer, and infrared spectra were recorded using $\mathrm{ABB}$ Bomem (MB Series) FT-IR spectrometer. All steady-state 

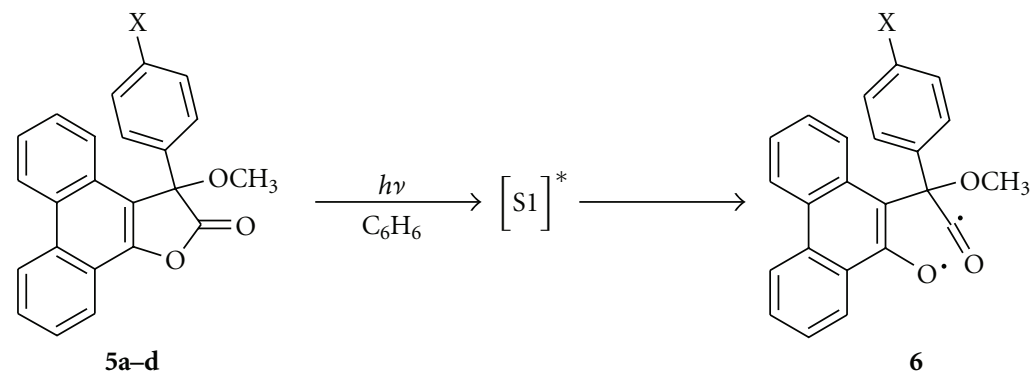

$\downarrow-\mathrm{CO}$<smiles>[X]c1ccc(C(=O)c2c(O)c3ccccc3c3ccccc23)cc1</smiles><smiles>[X]c1ccc(/C(OC)=C2\C(=O)c3ccccc3-c3ccccc32)cc1</smiles><smiles>[X]c1ccc(C(OC)c2c([O-])c3ccccc3c3ccccc23)cc1</smiles>
(a) $\mathrm{X}=\mathrm{H}$
(b) $\mathrm{X}=\mathrm{OCH}_{3}$
(c) $\mathrm{X}=\mathrm{CH}_{3}$
(d) $\mathrm{X}=\mathrm{Ph}$

Scheme 3

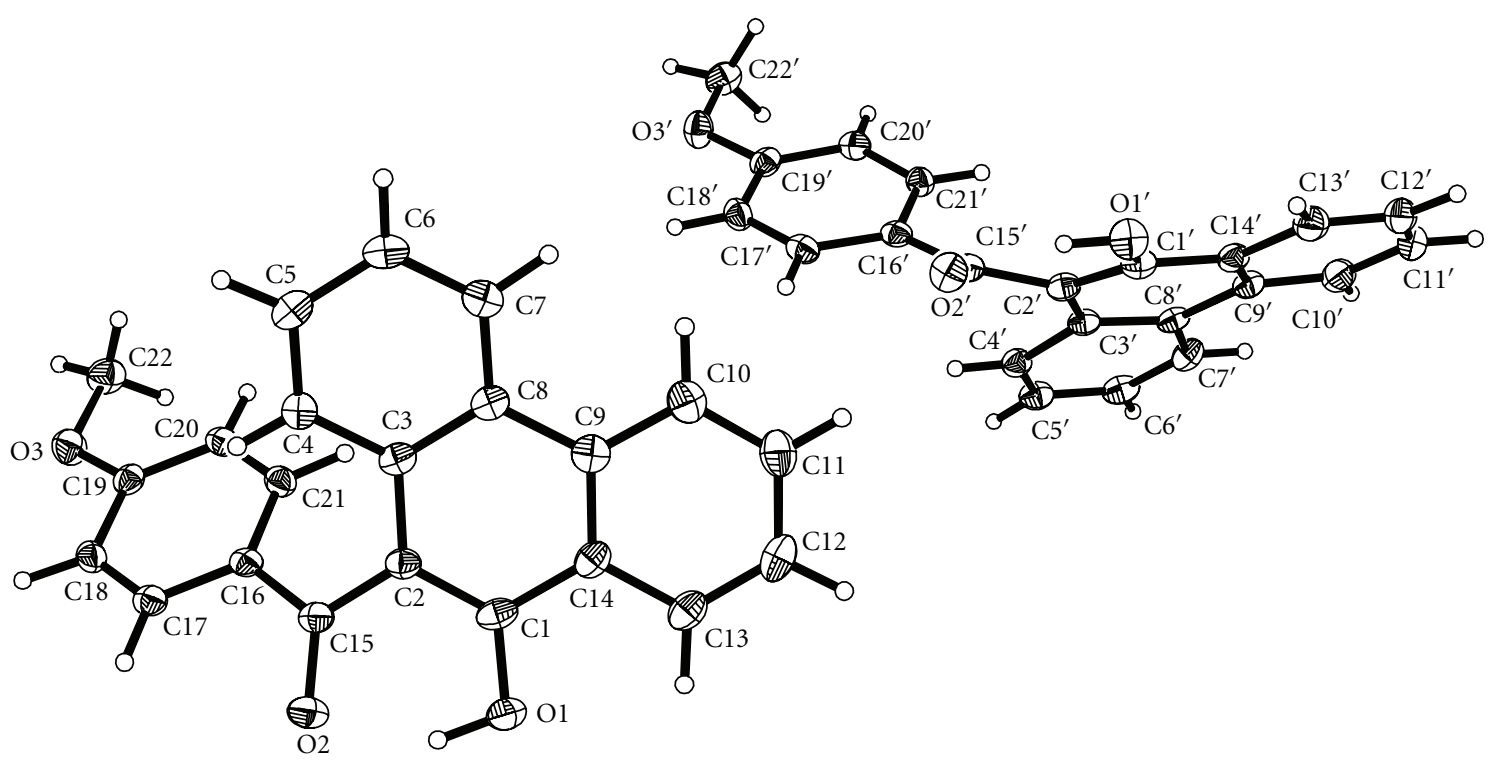

FIGURE 1: Projection view of the molecule $\mathbf{9 b}$ with $50 \%$ thermal ellipsoids. 


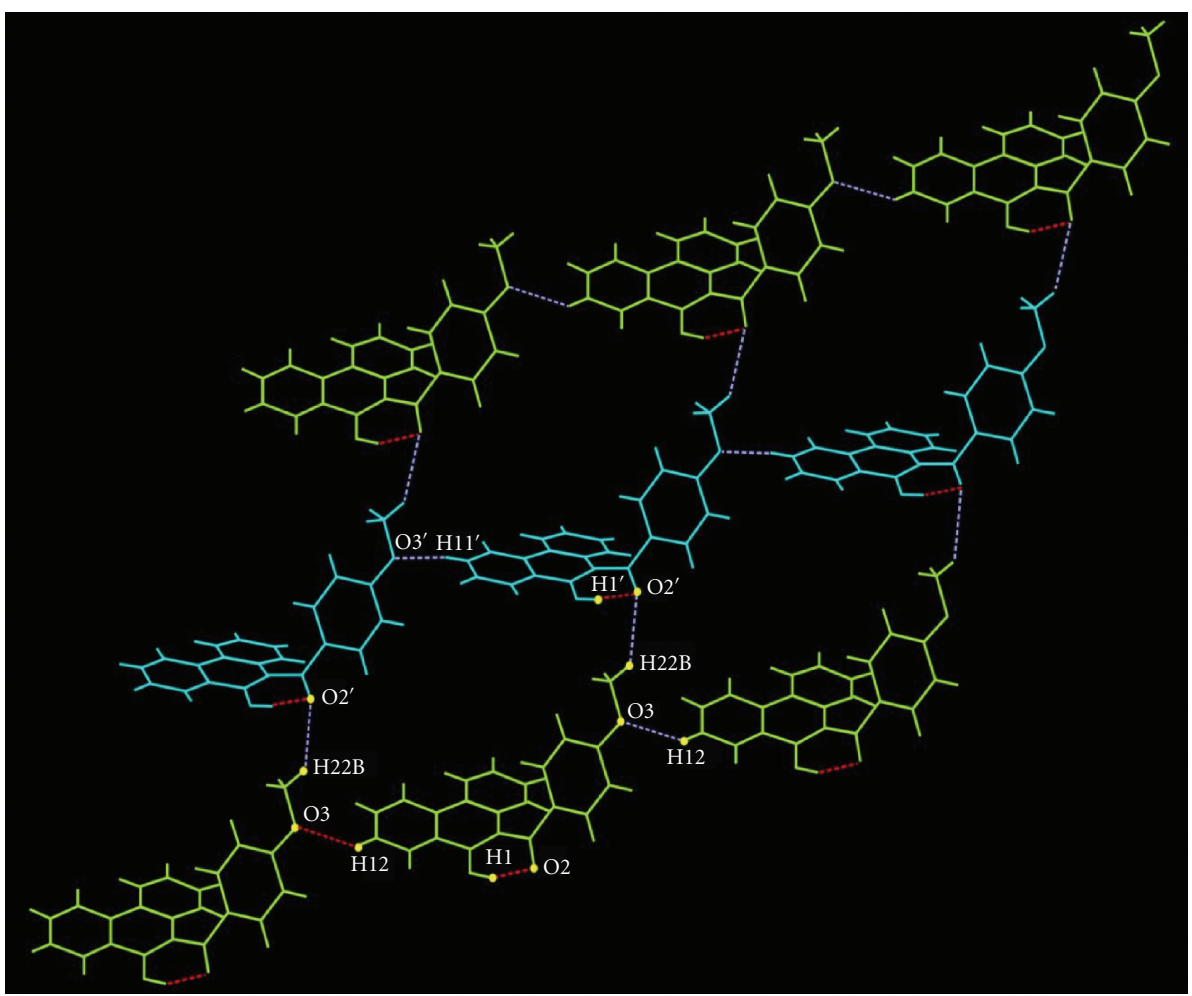

Figure 2: The square-like network and hydrogen bonding in the crystal lattice of $\mathbf{9 b}$.

irradiations were carried out using Rayonet Photochemical Reactor (RPR) at $300 \mathrm{~nm}$. Solvents for photolysis were purified and distilled before use. The ${ }^{1} \mathrm{H}$ and ${ }^{13} \mathrm{C}$ NMR spectra were recorded at 300 and $75 \mathrm{MHz}$, respectively, on a Bruker 300 FT-NMR spectrometer with tetramethylsilane (TMS) as internal standard. Chemical shifts are reported in parts per million (ppm) downfield of tetramethylsilane. Elemental analysis was performed using Elementar Systeme (Vario ELIII) at STIC, Kochi. Phenanthrenequinone, acetophenones, and ferrocene were purchased from E Merck and were used as obtained.

Typical Procedure for the Irradiation Experiment. A benzene solution of $\mathbf{5 a}-\mathbf{d}(0.73 \mathrm{mmol}$ in $150 \mathrm{~mL})$ was purged with nitrogen for $20 \mathrm{~min}$ and then irradiated for $2 \mathrm{~h}$. Progress of the reaction was monitored by TLC. Solvent was removed, and the residue was chromatographed over silica gel. Elution with a mixture $(4: 1)$ of hexane and dichloromethane gave 9a-d.

\section{9-Hydroxyphenanthren-10-yl(phenyl)methanone}

(9a). $(68 \%) ; \mathrm{mp} 136-138^{\circ} \mathrm{C}$; IR $\nu_{\max }(\mathrm{KBr}) 3428(\mathrm{OH}), 1620$ $(\mathrm{C}=\mathrm{O})$, and $1600 \mathrm{~cm}^{-1}$; UV $\lambda_{\max }\left(\mathrm{CH}_{3} \mathrm{CN}\right) 215(\varepsilon 17,200)$, 252 ( $\varepsilon$ 13,000), 296 ( $\varepsilon$ 7,600), $379 \mathrm{~nm}$ ( $\varepsilon$ 800); ${ }^{1} \mathrm{H}$ NMR $\left(300 \mathrm{MHz}, \mathrm{CDCl}_{3}\right) \delta 7.12-8.59(\mathrm{~m}$, aromatic and hydroxy protons); ${ }^{13} \mathrm{C} \mathrm{NMR}\left(75 \mathrm{MHz}, \mathrm{CDCl}_{3}\right) \delta 111.1,122.6,122.7$, $124.5,125.2,126.0,126.2,127.2,127.8,128.6,129.5,130.3$, $130.7,132.5,134.1,140.4,160.8,199.4$; MS, $m / z 298\left(\mathrm{M}^{+}\right)$, 239, 220, 165, 105, 77, and other peaks. Anal. Calcd. for $\mathrm{C}_{21} \mathrm{H}_{14} \mathrm{O}_{2}$ : C, 84.54; $\mathrm{H}, 4.74$. Found: C, 84.26; H, 4.81 .
9-Hydroxyphenanthren-10-yl(4-methoxyphenyl)methanone (9b). (66\%); mp $156-157^{\circ} \mathrm{C}$; IR $v_{\max }(\mathrm{KBr}) 3425(\mathrm{OH})$, $1615(\mathrm{C}=\mathrm{O})$, and $1600 \mathrm{~cm}^{-1}$; UV $\lambda_{\max }\left(\mathrm{CH}_{3} \mathrm{CN}\right) 251(\varepsilon$ 21,000), 293 ( $\varepsilon$ 9,500), $375 \mathrm{~nm}(\varepsilon 1,500) ;{ }^{1} \mathrm{H} \mathrm{NMR}\left(\mathrm{CDCl}_{3}\right)$ $\delta 3.86(3 \mathrm{H}, \mathrm{s}$, methoxy), 6.80-8.59 $(13 \mathrm{H}, \mathrm{m}$, aromatic and hydroxy protons); ${ }^{13} \mathrm{C} \mathrm{NMR}\left(\mathrm{CDCl}_{3}\right) \delta 55.0,104.0,114.0$, $122.4,122.9,124.4,125.0,126.2,127.0,127.6,128.3,129.4$, 130.3, 132.0, 159.0, 199.9; MS, $m / z 328\left(\mathrm{M}^{+}\right), 220,77$, and other peaks. Anal. Calcd. for $\mathrm{C}_{22} \mathrm{H}_{16} \mathrm{O}_{3}$ : C, 80.47; H, 4.90. Found: C, 80.18; H, 4.94.

2.1. Crystal Data. $\mathrm{C}_{22} \mathrm{H}_{16} \mathrm{O}_{3} \cdot M=328.35$, monoclinic, space group $\mathrm{P} 21, a=7.2298(3) \AA, b=13.7492(7) \AA, c=$ 16.0107(8) $\AA, \beta=92.621(2)^{\circ}, U=1589.86(13) \AA^{3}, Z=$ $4, D_{C}=1.372 \mathrm{mg} \mathrm{m}^{-3}, \mu=0.091 \mathrm{~mm}^{-1},(\operatorname{MoK} \alpha, \lambda=$ $0.71073 \AA$ ), $T=100$ (2) K. Of 27486 reflections measured on a Bruker Apex II diffractometer, 7421 were unique $\left(R_{\text {int }}=\right.$ 0.0496). The structure was solved by direct methods and refined on $F^{2}$ using full matrix refinement. Hydrogen atoms were refined isotropically. $R 1=0.0450(F$ values, $I>$ $2 \sigma(I)) . w R 2=0.0897\left(F^{2}\right.$ values, all data), goodnessof-fit $=1.023$, final difference map extremes +0.219 and $-0.222 \mathrm{eA}^{-3}$. Software: Shelxtl (Sheldrick, 2005).

9-Hydroxyphenanthren-10-yl(p-tolyl)methanone (9c). (64\%); mp $140-142^{\circ} \mathrm{C}$; IR $\nu_{\max }(\mathrm{KBr}), 3418(\mathrm{OH}), 1617$ $(\mathrm{C}=\mathrm{O})$, and $1600 \mathrm{~cm}^{-1}$; UV $\lambda_{\max }\left(\mathrm{CH}_{3} \mathrm{CN}\right) 217$ ( $\varepsilon$ 55,000), 255 ( $\varepsilon$ 52,000), 302 ( $\varepsilon$ 8,500), $376 \mathrm{~nm}\left(\varepsilon\right.$ 2,100); ${ }^{1} \mathrm{H}$ NMR $\left(\mathrm{CDCl}_{3}\right) \delta 1.75(\mathrm{~s}, 3 \mathrm{H}$, methyl), 6.80-8.59 (m, 15H, aromatic 
and hydroxy protons); MS, $m / z 312\left(\mathrm{M}^{+}\right), 220,163,91$, and other peaks. Anal. Calcd for $\mathrm{C}_{27} \mathrm{H}_{18} \mathrm{O}_{2}$ : $\mathrm{C}, 80.34 ; \mathrm{H}, 5.39$. Found: C, 80.30; H, 5.14.

9-Hydroxyphenanthren-10-yl(diphenyl)methanone (9d). (65\%); mp $153-155^{\circ} \mathrm{C}$; IR $\nu_{\max }(\mathrm{KBr}), 3420(\mathrm{OH}), 1615$ $(\mathrm{C}=\mathrm{O})$, and $1600 \mathrm{~cm}^{-1}$; UV $\lambda_{\max }\left(\mathrm{CH}_{3} \mathrm{CN}\right) 257(\varepsilon 22,000)$, 275 ( $\varepsilon 10,500), 304$ ( $\varepsilon 5,000), 355 \mathrm{~nm}(\varepsilon 2,000) ;{ }^{1} \mathrm{H}$ NMR $\left(\mathrm{CDCl}_{3}\right) \delta 6.80-8.59(\mathrm{~m}$, aromatic and hydroxy protons); MS, $m / z 374\left(\mathrm{M}^{+}\right), 220,163,77$, and other peaks. Anal. Calcd. for $\mathrm{C}_{27} \mathrm{H}_{18} \mathrm{O}_{2}$ : C, 86.61; $\mathrm{H}, 4.85$. Found: C, 86.38; H, 5.14 .

Irradiation of $\mathbf{5 a}$ in the Presence of Ferrocene. A benzene solution of $\mathbf{5 a}(250 \mathrm{mg}, 0.74 \mathrm{mmol}$ in $150 \mathrm{~mL})$ containing ferrocene ( $120 \mathrm{mg}, 0.74 \mathrm{mmol}$ ) was purged with nitrogen for $20 \mathrm{~min}$ and then irradiated (RPR, $300 \mathrm{~nm}$ ) for $2 \mathrm{~h}$. Progress of the reaction was monitored by TLC. Solvent was removed, and the residue was charged to a column of silica gel. Elution with a mixture $(4: 1)$ of hexane and dichloromethane gave 9 a (120 mg, 60\%).

Irradiation of $\mathbf{5 a}$ in the Presence of Dimethyl Acetylenedicarboxylate (DMAD). A benzene solution of $\mathbf{5 a}(250 \mathrm{mg}$, $0.73 \mathrm{mmol}$ in $150 \mathrm{~mL}$ ) containing DMAD (590 mg, $4.14 \mathrm{mmol}$ ) was purged with nitrogen for $20 \mathrm{~min}$ and then irradiated (RPR, $350 \mathrm{~nm}$ ) for $2 \mathrm{~h}$. The reaction was monitored by TLC. Solvent was removed, and the residue was charged to a column of silica gel. Elution with a mixture (4:1) of hexane and dichloromethane gave $9 \mathrm{a}$ (140 mg, $64 \%)$.

Irradiation of $\mathbf{5 a}$ in the presence of 2-propanol. A benzene solution of $\mathbf{5 a}(250 \mathrm{mg}, 0.73 \mathrm{mmol}$ in $150 \mathrm{~mL})$ containing 2-propanol $(15 \mathrm{~mL}, 0.20 \mathrm{mmol})$ was purged with nitrogen for $20 \mathrm{~min}$ and then irradiated (RPR, $350 \mathrm{~nm}$ ) for $2 \mathrm{~h}$. The reaction was monitored by TLC. Solvent was removed and the residue was charged to a column of silica gel. Elution with a mixture $(4: 1)$ of hexane and dichloromethane gave 9a (140 mg, 64\%).

\section{Acknowledgments}

The authors are thankful to Sophisticated Analytical Instrumentation Facility, CUSAT, Kochi for elemental analysis. Funding from the National Science Foundation for the purchase of the X-ray diffraction system (Award no. 0420497) and financial support by DST and CSIR are gratefully acknowledged.

\section{References}

[1] Y. S. Rao, "Recent advances in the chemistry of unsaturated lactones," Chemical Reviews, vol. 76, no. 5, pp. 625-694, 1976.

[2] A. Padwa, T. Brookhart, D. Dehm, and G. Wubbels, "Migratory aptitude studies in the photochemical rearrangement of 2(5H)-furanones," Journal of the American Chemical Society, vol. 100, no. 26, pp. 8247-8259, 1978.
[3] K. R. Gopidas, D. R. Cyr, P. K. Das, and M. V. George, "Photochemical and thermal transformations of 3-benzyl$2(3 \mathrm{H})$-furanones and related substrates," Journal of Organic Chemistry, vol. 52, no. 25, pp. 5505-5511, 1987.

[4] S. Pratapan, K. Ashok, D. R. Cyr, P. K. Das, and M. V. George, "Substituent effects in the photochemistry of 5-aryl3,3-diphenyl-2(3H)-furanones. Steady-state and laser flash photolysis studies," Journal of Organic Chemistry, vol. 53, no. 25, pp. 5826-5831, 1988.

[5] L. Fillol, M. A. Miranda, I. M. Morera, and H. Sheikh, "Photochemistry of $2(3 \mathrm{H})$ - and $2(5 \mathrm{H})$-furanones," Heterocycles, vol. 31, no. 4, pp. 751-782, 1990.

[6] O. L. Chapman and C. L. McIntosh, "Photochemical decarbonylation of unsaturated lactones and carbonates," Journal of the Chemical Society D, no. 8, pp. 383-384, 1971.

[7] R. Martinez-Utrilla and A. M. Miranda, "Photochemistry of 5-aryl-2(3H)-furanones. : A new route to the synthesis of chromones," Tetrahedron, vol. 37, pp. 2111-2114, 1981.

[8] S. Breda, I. Reva, and R. Fausto, "UV-induced unimolecular photochemistry of $2(5 \mathrm{H})$-furanone and $2(5 \mathrm{H})$-thiophenone isolated in low temperature inert matrices," Vibrational Spectroscopy, vol. 50, no. 1, pp. 57-67, 2009.

[9] A. Yogev and Y. Mazur, "Irradiation of enol lactones," Journal of the American Chemical Society, vol. 87, no. 15, pp. 35203521, 1965.

[10] C. D. Gutsche and B. A. M. Oude-Alink, "The photoinduced alcoholysis of 3,4-dihydrocoumarin and related compounds," Journal of the American Chemical Society, vol. 90, no. 21, pp. 5855-5861, 1968.

[11] I. S. Krull and D. R. Arnold, "The Hg senitized vapor phase photolysis of $\gamma$-crotonolactone and simple butenolides," Tetrahedron Letters, vol. 25, no. 16, pp. 1247-1249, 1969.

[12] G. Rio and J. C. Hardy, "Triphenyl-3,4,5 H-5 furannone-2, acide cis-benzoyl-3 diphenyl-2,3 acrylique et derives," Bulletin de la Societe Chimique de France, vol. 10, pp. 3572-3578, 1970.

[13] B. B. Lohray, C. V. Kumar, P. K. Das, and M. V. George, "Photochemical and thermal transformations of $2(3 \mathrm{H})$-furanones and bis(benzofuranones). A laser flash photolysis study," Journal of the American Chemical Society, vol. 106, no. 24, pp. 7352-7359, 1984.

[14] K. R. Gopidas, B. B. Lohray, S. Rajadurai, P. K. Das, and M. V. George, "Sensitized photorearrangement of 3,3,5-triaryl$2(3 \mathrm{H})$-furanones to 3,4,5-triaryl-2(5H)-furanones. Steadystate and laser flash photolysis investigations," Journal of Organic Chemistry, vol. 52, no. 13, pp. 2831-2838, 1987.

[15] G. Rio and J. C. Hardy, "Triphenyl-3,4,5 H-5 furannone-2, acide cis- benzoyl-3 diphenyl-2,3 acrylique et derives," Bulletin de la Societe Chimique de France, vol. 10, pp. 3572-3578, 1970.

[16] P. J. Wagner and R. G. Zepp, “ $\gamma$-vs. $\delta$-Hydrogen abstraction in the photochemistry of $\beta$-alkoxy ketones. An overlooked reaction of hydroxy biradicals," Journal of the American Chemical Society, vol. 93, no. 19, pp. 4958-4959, 1971.

[17] A. M. Jacob, R. K. Thumpakkara, S. Prathapan, and B. Jose, "Synthesis of 3,3-dimethoxy-2-aryl-2,3-dihydro-1-oxacyclopenta[1] phenanthren-2-ols and their conversion to 2(3H)- and 3(2H)-furanones," Tetrahedron, vol. 61, no. 19, pp. 4601-4607, 2005. 


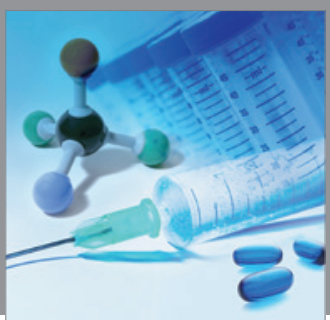

International Journal of

Medicinal Chemistry

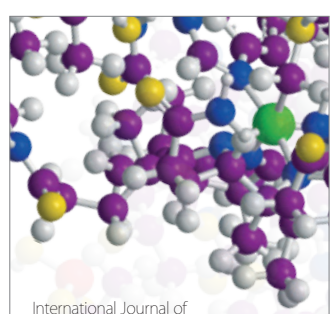

Carbohydrate Chemistry

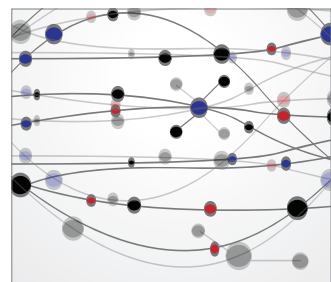

The Scientific World Journal
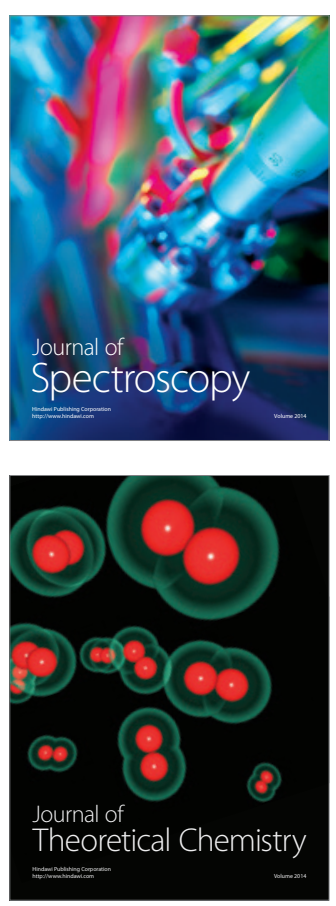
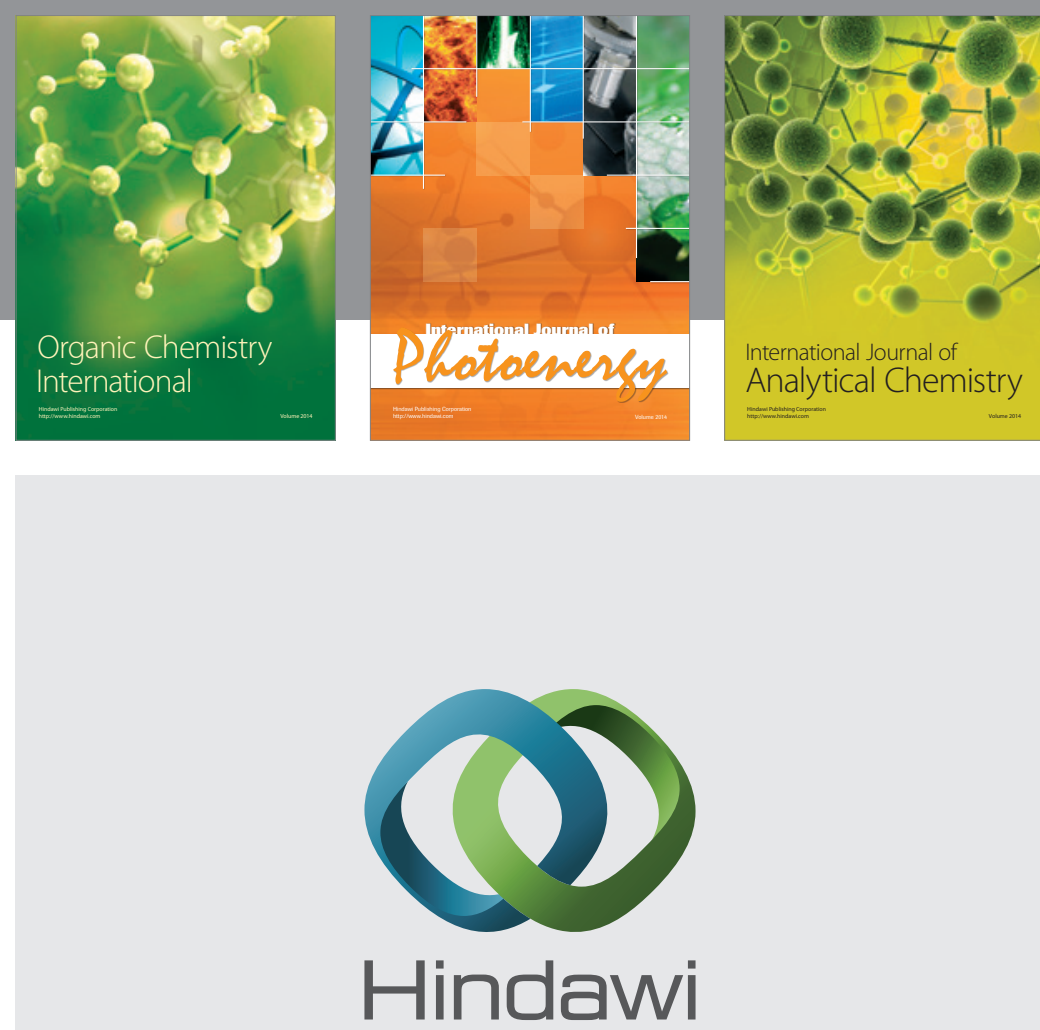

Submit your manuscripts at

http://www.hindawi.com
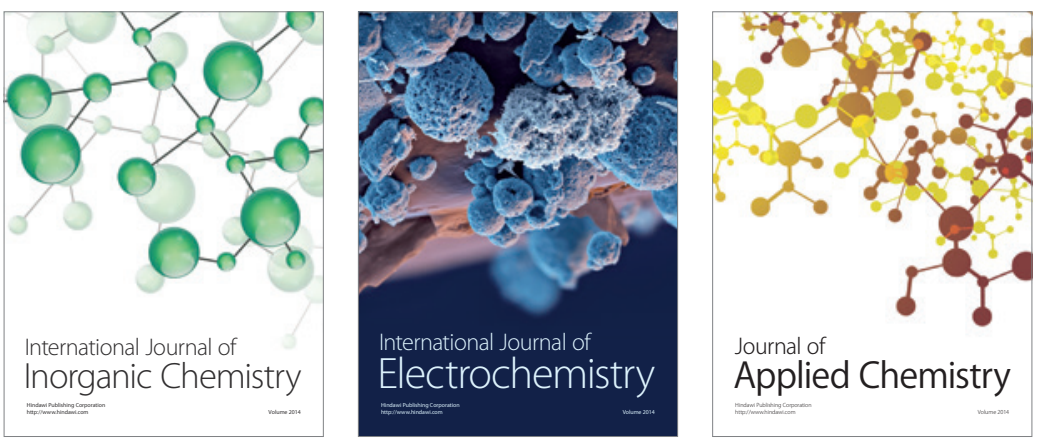

Journal of

Applied Chemistry
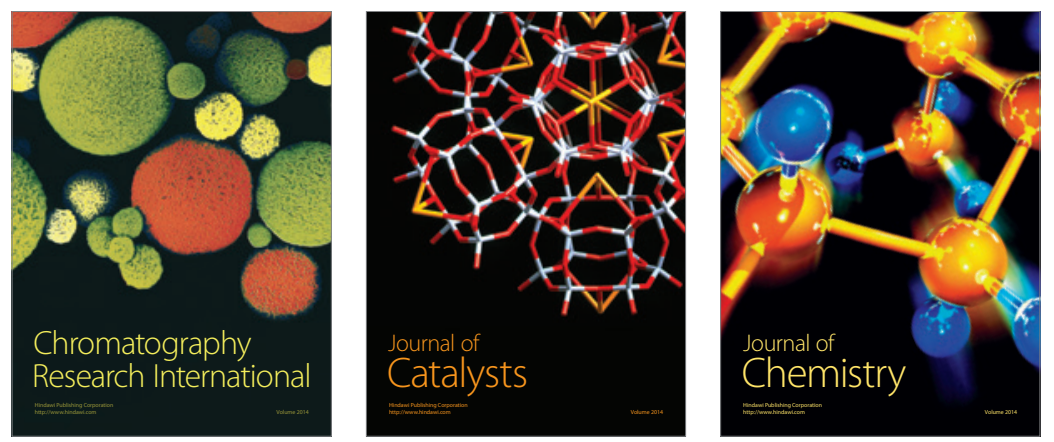
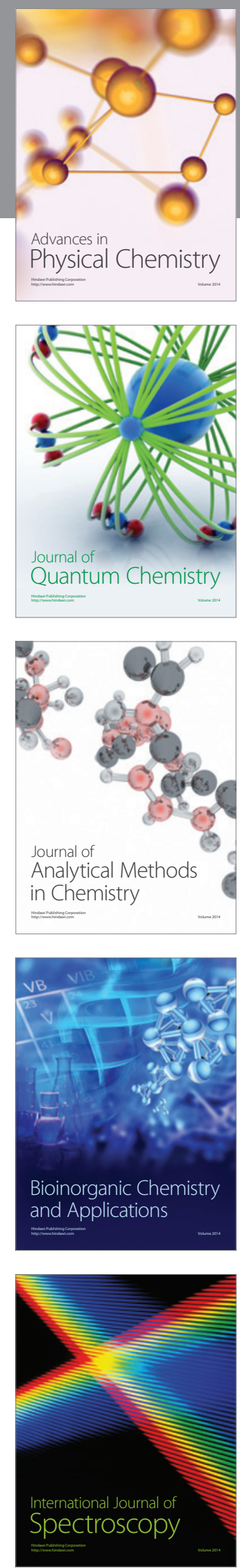